\title{
Assessment of subjective sleep quality in iron deficiency anaemia
}

\author{
Semiz Murat ${ }^{1}$, Uslu Ali $^{2}$, Korkmaz Serdal ${ }^{3}$, Demir Süleyman ${ }^{4}$, Parlak İlknur ${ }^{5}$, \\ Sencan Mehmet ${ }^{6}$, Aydin Bahattin ${ }^{5}$, Uncu Tunahan ${ }^{5}$
}

1. Gülhane Military Medical Faculty, Department of Psychiatry, Ankara, Turkey.

2. Eskişehir Military Hospital, Department of Internal Medicine, Eskisehir, Turkey.

3. Kayseri Education and Research Hospital, Division of Hematology, Kayseri, Turkey.

4. Department of Psychiatry, Dicle University, Diyarbakir, Turkey.

5. Cumhuriyet University Faculty of Medicine, Department of Internal Medicine, Sivas, Turkey.

6. Cumhuriyet University Faculty of Medicine, Department of Hematology, Sivas, Turkey.

\begin{abstract}
Objectives: We aimed to assess the effect of anemia on subjective sleep quality in patients with iron deficiency anemia (IDA).

Methods: One hundred and four patients diagnosed with IDA and 80 healthy individuals, who are gender and age matched, were included in the study. All participants were requested to fill 3 forms: a socio-demographic form (age, gender, marital status, income level and educational status), hospital anxiety and depression (HAD) scale and pittsburgh sleep quality index (PSQI).

Results: According to the HAD scale, the average anxiety score was found $9.24 \pm 4.37$ in patients and $7.58 \pm 4.07$ in controls. And, the average depression score was $7.53 \pm 4.10$ in patients and $6.41 \pm 2.74$ in controls. The total sleep quality score was $6.71 \pm 3.02$ in patients and $4.11 \pm 1.64$ in controls. There was a statistically significant difference in terms of anxiety, depression and sleep quality scores. Linear regression analysis showed no association between anxiety and depression with poor sleeping.
\end{abstract}

Conclusion: IDA affects sleep quality irrespective of psychological symptoms such as depression and anxiety.

Keywords: Iron deficiency anemia, sleep quality, anxiety

DOI: http://dx.doi.org/10.4314/ahs.v15i2.40

\section{Introduction}

After a negative iron balance in the body due to reasons such as chronic blood loss, increased iron demand, and absorption disorder, hemoglobin synthesis is compensated by mobilization of iron from stores and when the stores of iron fail to release adequate iron, iron deficiency anemia (IDA) develops ${ }^{1}$. Just like in our country, iron deficiency is the most common cause of anemia in the world and is more prevalent in women than $\operatorname{men}^{2,3}$. It has been known that more than $30 \%$ of those attending to hospitals in developed countries are anemic and the said ratio is much higher in developing countries.

\section{Corresponding author:}

Semiz Murat,

Gülhane Tip Akademisi Psikiyatri AD,

TR-06020, Ankara, Turkey.

Email:drmuratsemiz@hotmail.com
In developed countries, $3 \%$ of adult males, $20 \%$ of adult females and $50 \%$ of pregnant women have iron deficiency anemia ${ }^{4,5}$. Loss of appetite, tiredness, pale skin, lethargy, headache, tinnitus and impairments in cognitive and intellectual functions can be observed in $\mathrm{IDA}^{6}$. Iron plays a key role in the metabolism of monoamines in the brain thus iron deficiency leads to symptoms such as apathy, drowsiness, irritability and lack of attention occur due to impaired monoamine oxidase activity $^{7}$. Patients affected from iron deficiency display many behavioral and emotional signs and have symptoms similar to the ones in depressive individuals ${ }^{8}$.

Sleep is the period of physiological, periodic and reversible changes in consciousness and behaviour'. It is defined as a reversible state where interaction of the organism with the environment is lost temporarily, partially and periodically ${ }^{10}$. Nearly $30-33 \%$ of the society has a significant sleep problem. The said ratio is higher in older adults, those having a psychiatric disorder and specific groups with learning difficulties ${ }^{11-14}$. In various 
studies, advanced age, female gender, stress, depression, income level and educational status), hospital anxiety anxiety, alcohol, substance abuse and physical diseases and depression scale and Pittsburgh sleep quality index. are the important factors causing sleep disorders ${ }^{15,16}$. Due to the key role of iron in the metabolism of mon- hospital anxiety and depression scale (HAD). As the oamines in the brain and the role of the same monoam- scores increase, depression and anxiety increase $\mathrm{e}^{16-17}$. ines in sleep physiology, we stipulated that sleep quality The Turkish version was developed by Aydemir ${ }^{18}$ et al. might deteriorate in IDA. In this context, studies usual- The Pittsburgh sleep quality index (PSQI) was used to ly have been performed in pediatric populations. To the measure sleep disturbance. It is consisted of 19 items best of our knowledge, there exist no studies examin- and over 7 domains that include subjective sleep quality, ing subjective sleep quality in adult patients with IDA. sleep latency, sleep duration, habitual sleep efficiency, Therefore, we aimed evaluating sleep quality in adult sleep disturbance, use of sleep medications and daypatients diagnosed with IDA.

\section{Materials and methods}

Our study is a prospective and cross-sectional study which has been carried out at Cumhuriyet University, medical faculty, hematology clinic between January 2013 and June 2013. Ethical committee approval was obtained from the ethics commitee of the medical faculty of Cumhuriyet University, and the study was in accordance with the declaration of Helsinki. One hundred and four patients diagnosed with IDA and gender and age matched 80 healthy individuals were included in the study. Loss of appetite and tiredness were the most common presentations. It was confirmed that there were no accompanying neurological or endocrinological diseases in patients with IDA.

The diagnosis of IDA was made by evaluating the levels of hemoglobin, transferrin saturation -calculated by the ratio of serum iron to serum iron binding capacity- and Result

ferritin. Hemoglobin level below $13 \mathrm{mg} / \mathrm{dL}$ in men and The patient population (average age: $32.57 \pm 10.19$ $12 \mathrm{mg} / \mathrm{dL}$ in women, transferrin saturation ratio below years) were composed of 104 patients [81 (77.9\%) fe$15 \%$, and ferritin level below $15 \mathrm{ng} / \mathrm{mL}$ indicated IDA. male and $23(22.1 \%)$ male]. The control group (average The control group was composed of healthy volunteers age: $30.44 \pm 9.98$ years) had similar socio-demographwho were regular blood donors in our hospital. Those ic characteristics and were composed of 80 healthy having systemic diseases such as diabetes mellitus, hy- individuals [61 (76.2\%) female and 19 (23.8\%) male]. pertension, congestive heart failure, chronic obstructive In terms of age and gender distribution, there was no pulmonary disease, coronary artery disease, rheumatoid statistically significant difference between the groups arthritis, systemic lupus erythematosus and ankylosing $\left(t=1.42 \mathrm{p}=0.16\right.$ ve $\left.\mathrm{x}^{2}=0.069 \mathrm{p}=0.793\right)$. The socio-despondylitis and any medication use were excluded from mographic characteristics of the study groups are given the study. The participants were asked to complete a in Table 1

socio-demographic form (age, gender, marital status, In terms of haemoglobin, hematocrit and MCV val-
Table 1. Socio-demographic characteristics of the study groups

\begin{tabular}{lcccc}
\hline & $\begin{array}{c}\text { Patients } \\
\mathrm{n}(\%)\end{array}$ & $\begin{array}{c}\text { Controls } \\
\mathrm{n}(\%)\end{array}$ & $\begin{array}{c}\text { Statistics } \\
\left(\mathrm{x}^{2}\right)\end{array}$ & $\mathrm{p}$ value \\
\hline $\begin{array}{l}\text { Gender } \\
\text { Female }\end{array}$ & $81(77.9)$ & $61(76.2)$ & 0.069 & 0.793 \\
$\quad$ Male & $23(22.1)$ & $19(23.8)$ & & \\
$\begin{array}{l}\text { Educational status } \\
\text { Primary school }\end{array}$ & $33(31.7)$ & $27(33.8)$ & & \\
$\quad$ Secondary school & $19(18.3)$ & $16(20.0)$ & 0.699 & 0.874 \\
High school & $36(34.6)$ & $28(35.0)$ & & \\
University & $16(15.4)$ & $9(11.2)$ & & 0.454 \\
Marital status & & & & \\
$\quad$ Married & $66(63.5)$ & $55(68.8)$ & 0.562 & \\
$\quad$ Single & $38(36.5)$ & $25(31.2)$ & & \\
Income status & & & & \\
$\quad$ Low-income & $26(25.0)$ & $21(26.2)$ & 0.038 & \\
Middle-income & $66(63.5)$ & $50(62.5)$ & & \\
$\quad$ High-income & $12(11.5)$ & $9(11.2)$ & & \\
\hline
\end{tabular}

ues, there was a statistically significant difference be- groups. The detailed hemogram values of the groups tween the groups $(\mathrm{t}=16.95, \mathrm{p}=0.001 ; \mathrm{t}=6.77, \mathrm{p}=0.001 ; \quad$ are shown in Table 2 . In the patient group, the average $\mathrm{t}=15.78, \mathrm{p}=0.001$, respectively). The other hemogram serum ferritin level and total iron binding capacity were parameters did not show any differences between the

Table 2. Hemogram values

\begin{tabular}{lcccc}
\hline & $\begin{array}{c}\text { Patients } \\
\text { mean } \pm \mathrm{SD}\end{array}$ & $\begin{array}{c}\text { Controls } \\
\text { mean } \pm \mathrm{SD}\end{array}$ & $\mathrm{T}$ & $\mathrm{p}$ \\
\hline Haemoglobin & $10.05 \pm 1.47$ & $13.12 \pm 0.76$ & 16.96 & $\mathbf{0 . 0 0 1}^{*}$ \\
Hematocrit & $32.62 \pm 3.64$ & $36.11 \pm 3.21$ & 6.77 & $\mathbf{0 . 0 0 1}^{*}$ \\
MCV & $70.28 \pm 7.84$ & $85.24 \pm 3.67$ & 15.78 & $\mathbf{0 . 0 0 1}^{*}$ \\
White Blood Cell & $6.31 \pm 1.37$ & $6.16 \pm 1.48$ & 0.67 & 0.504 \\
MCH & $21.93 \pm 3.43$ & $21.81 \pm 3.31$ & 0.04 & 0.958 \\
MCHC & $30.90 \pm 3.28$ & $31.07 \pm 3.60$ & 0.33 & 0.741 \\
\hline * $<0.05$, significant & & & &
\end{tabular}

$\mathrm{p}<0.05$, significan

MCV: mean corpuscular volume

corpuscular hemoglobin

MCHC: mean corpuscular hemoglobin concentration 
9.24 \pm 4.37 in patients and $7.58 \pm 4.07$ in controls $(t=2.64$, and $4.11 \pm 1.64$ in controls. In terms of total PSQI score, $\mathrm{p}=0.009)$. The average depression score was $7.53 \pm 4.10$ there was a statistically significant difference between in patients and $6.41 \pm 2.74$ in controls $(t=2.10, p=0.037)$. the groups $(t=6.94, p<0.001)$.

There was a statistically significant difference in terms of anxiety and depression scores. The number of pa- With respect to the subscales of PSQI, subjective sleep tients who had an anxiety level above the cut-off score score was found $1.33 \pm 0.81$ in patients and $0.85 \pm 0.58$ in was $45(43.3 \%)$ and it was $22(27.5 \%)$ in the control controls, so, we have found a statistically significant difgroup $\left(\mathrm{x}^{2}=4.856 \mathrm{p}=0.028\right)$. The number of patients ference between groups $(\mathrm{t}=4.48, \mathrm{p}<0.001)$. Sleep diswho had a depression score above the cut-off score was order score was $1.63 \pm 0.75$ in patients and $0.93 \pm 0.57$ in $49(47.1 \%)$ and it was $26(32.5 \%)$ in the control group controls, so, we have found a statistically significant dif$\left(\mathrm{x}^{2}=4.00, \mathrm{p}=0.045\right)$.

In PSQI, 70 (67.3\%) patients and $32(40.5 \%)$ controls reported a bad sleep quality. The number of patients who reported a bad sleep quality were statistically significantly higher than the controls $\left(\mathrm{x}^{2}=13.072 ; \mathrm{p}<0.001\right)$ The total sleep quality score was $6.71 \pm 3.02$ in patient ference between groups $(\mathrm{t}=7.04, \mathrm{p}<0.001)$. PSQI sucbscale scores of the groups are given in Table 3 . In the regression analysis, we evaluated whether the presence of "sleep disorder" is associated with depression and anxiety. Linear regression analysis showed no association of anxiety (partial correlation coefficient: -0.176 ; $\mathrm{p}$ $=0.101$ ) and depression (partial correlation coefficient $-0.086 ; \mathrm{p}=0.430)$ with poor sleeping.

Table 3. PSQI subscales

\begin{tabular}{|c|c|c|c|c|}
\hline & Patients & Controls & & \\
\hline & $($ mean $\pm \mathrm{SD})$ & $($ mean $\pm \mathrm{SD})$ & $(\mathrm{t})$ & (p) \\
\hline Subjective sleep quality & $1.33 \pm 0.81$ & $0.85 \pm 0.58$ & 4.48 & $0.001 *$ \\
\hline Sleep latency & $1.33 \pm 0.81$ & $0.73 \pm 0.64$ & 5.49 & $0.001^{*}$ \\
\hline Sleep duration & $0.62 \pm 0.84$ & $0.56 \pm 0.59$ & 0.48 & 0.632 \\
\hline Habitual sleep efficiency & $0.60 \pm 0.77$ & $0.38 \pm 0.51$ & 2.22 & 0.028 \\
\hline Sleep disturbances & $1.63 \pm 0.75$ & $0.93 \pm 0.57$ & 7.04 & $0.001^{*}$ \\
\hline Use of sleep medication & $0.02 \pm 0.20$ & $0.00 \pm 0.00$ & 0.88 & 0.382 \\
\hline General dysfunction & $1.19 \pm 0.89$ & $0.68 \pm 0.63$ & 4.40 & $0.001 *$ \\
\hline Total sleep disorder & $6.71 \pm 3.02$ & $4.11 \pm 1.64$ & 6.94 & $0.001 "$ \\
\hline
\end{tabular}

$\mathrm{p}<0.05$, significant
Iron deficiency has been reported to cause behavioral and developmental symptoms by affecting transmitters such as serotonin, noradrenaline and dopamine, myelination, and the metabolic activity in the neurons $\mathrm{s}^{21,22}$. It has been also reported that brain functions such as cognition and learning are affected in patients with $\mathrm{IDA}^{23}$. Peirano et al. ${ }^{24}$ reported that relative to controls, children with IDA showed: a) longer duration of REM sleep episodes in the first third and shorter in the last third; b) more REM sleep episodes in the first third and fewer in the second third; and c) shorter latency to the first REM sleep episode and shorter NREM stage 2. So, their results show that IDA is associated with long-lasting alterations in the temporal organization of sleep patterns ${ }^{24}$. Peirano et al. ${ }^{24}$ suggested that the changes in the neurotransmitter metabolism due to iron deficiency, pscyhological status or a possible restless leg syndrome (RLS) affected sleep negatively. These results could be explained by some mechanisms. One possible explanation for the differences that long-lasting effects of iron deficiency on the developing dopamine (DA) system are a promising example ${ }^{25,26}$.

Iron has a complex effect on dopaminergic function. It is a cofactor for tyrosine hydroxylase and is integral to D2 receptor function ${ }^{27}$. Neuromodulation by the DA system plays an important role in sleep regulation, including the modulation of REM sleep quality, quantity, and timing ${ }^{28,29}$. Holst et al. ${ }^{30}$, studied sleep-wake regulation in humans and combined pharmacogenetic and neurophysiologic methods to analyze the effects of the 3'-UTR variable-number-tandem-repeat polymorphism of the gene (DAT1, SLC6A3) encoding dopamine transporter. Their findings suggested that the dopamine transporter contributes to homeostatic sleep-wake regulation in humans. Fifel et al. ${ }^{31}$, investigated alterations of circadian rhythms in non-human primate models following lesion of the dopaminergic nigro-striatal system.

Their results are of clinical importance and stress that sleep/wake disturbances associated with DA loss may be more severely affected than previously thought, in particular in sub-optimal lighting conditions. The dynamic balance between neurotransmitter systems is another important consideration. The ultradian alternation of NREM sleep/REM sleep appears to be controlled by a permanent interacting balance between brainstem aminergic and cholinergic neuronal discharges ${ }^{32}$. An additional explanation could be differing mounts of sleep alterations. In particular, RLS and petiodic limb movements during sleep have been associated with conditions characterized by compromised iron status $^{33}$. It has been known that iron deficiency plays an important role in the physiopathology of the RLS characterized by an irresistible urge to move legs as well as motor restlessness.

Iron treatment has been thought to increase sleep quality of the patients by decreasing RLS complaints. In a study of Allen et al. ${ }^{34}$, prevalence of clinically signifcant RLS (RLS sufferers) was $23.9 \%$ in 251 patients with IDA, nine times higher than the general population. In another study, the said ratio was reported as $40 \% 35$. Patients with RLS were excluded from this study. In the present study, nearly $68 \%$ of the patients with IDA were shown to have an impaired sleep quality. Our findings support the idea that sleep quality is impaired in a significant portion of patients with IDA.

Depression and anxiety disorders are among the psychological disorders that affect sleep quality negatively. In a study conducted by Onder et al., depressive disorder was found to be a common disorder in patients with anemia $a^{36}$. In our study, similar to the literature, a major portion (nearly 45\%) of the patients had high anxiety and depression scores. Son et al. reported that cognitive functions were worse in anemia patients when compared to healthy controls, which was shown to be associated with depressive disorder ${ }^{37}$. In the present study, logistic regression analysis showed that anemia affected sleep quality irrespective of the psychological symptoms.

To the best of our knowledge, there is no study in the literature that evaluated the association between laboratory values and sleep quality in adult population having IDA. Yehuda and collageus $^{38}$, examined hemoglobin levels and showed that sleep-deprived attention deficit hyperactivity disorder (ADHD) patients also suffer also from iron deficiency. However, Yehuda et al..$^{38}$, were not clear if iron deficiency was one of the core symptoms of this pediatric group or it was a consequence of poor food intake habits. Another study of the Yehuda $^{39}$, showed that iron deficiency might be associated with sleep disturbances and lower intelligence quality at pediatric population.

We have found no significant relation between the sleep quality and laboratory values of the patients. In our study, lack of significant correlation between lab- 
oratory values and sleep quality scores was not an ex- 5. Lee R G. Iron deficiency and iron deficiency anemia pected result. Shariatpanaahi et al. ${ }^{40}$ reported that there Eds: Lee R.G, Bithell C.T, Foerster J: wintrobe's clinical was a weak correlation between serum ferritin level and Hematology 10 th edition,1999. Lea-Febiger. Chapter depression. In another study, it was shown that serum 34:979-1010.

ferritin and hemoglobin levels had no significant rela- 6. Gümrük F, Altay Ç: Demir metabolizması ve demi tion with depression level. Similar to the results of the eksikliği anemisi. Katk1 Pediatri Dergisi. 1995;3:265-85. previous studies, the results of our study showed that 7. Shoham S, Youdim MBH. Iron involvement in the sleep quality level could not be evaluated through neural damage and microgliosis in models of neurohemogram, serum iron and ferritin levels in patients degenerative diseases. Cell Mol Biol (Noisy-le-grand). with IDA.

\section{Limitations}

Our study had some limitations. The first limitation was evaluating depression anxiety and sleep quality through self-report scales. The second limitation was not performing polysomnographic measurements. There is a (by EEG or by Actigraph) and subjective evaluation (PSQI). Conducting a cross-sectional study could have affected the results, too.

\section{Conclusion}

Subjective sleep quality was evaluated in patients with IDA in the present study. The results showed that IDA affects sleep quality irrespective of psychological symptoms such as depression and anxiety. And also, it was shown that subjective sleep quality was worse in patients with IDA when compared to the healthy controls. The effects of anemia treatment on sleep quality were not assessed due to the cross-sectional nature of the study. Further studies, where anemia patients should be followed-up for an extended period of time and evaluated by polysomnography, are required.

\section{Conflict of interest statement:}

There is no conflict of interest.

\section{References}

1. Dündar S.Demir eksikliği anemisi.Yasavul Ü, Çelik I, Arıcı M. In Hacettepe İç Hastalıkları kitabı . 2B. Ankara, Hacettepe Üniversitesi Yayınlar1, 2004; p.867-72.

2. De Falco L, Sanchez M, Silvestri L, Kannengiesser C, Muckenthaler MU, Iolascon A, et al. Iron refractory iron deficiency anemia. Haematologica. 2013;98:845-53. cian? Balkan Med J 2010;27:31-4.

4. Beutler E, Lichman M A, Coller B S:Iron deficiency, ed. Williams E, Hematology fifth edition .Philadelphia $1995 ; 4905-11$ 15. Chokroverty S. Overview of sleep \& sleep disorders. Indian J Med Res. 2010;131:126-40.

16. Gulec Cakın T, Yoruk O, Gulec M, Selvi Y, Boysan M, Oral E, Yucel A, Mazlumoglu MR. Benefits of submucous resection on sleep quality, daytime and dream Biological Rhythms. 2013;11:227-36.

7. Zigmond AS, Snaith RP. The hospital anxiety and depression scale. Acta Psychiatr. Scand. 1983;67:36170.

18. Aydemir Ö, Güvenir T, Küey L. Validity and realibility of Turkish version of Hospital Anxiety and Depression Scale. Turkish Journal of Psychiatry 1997;8:280-7. 19. Buysse DJ, Reynolds CF, Monk TH, Berman SR, Kupfer DJ. The Pittsburgh Sleep Quality Index: a new instrument for psychiatric practice and research. Psychiatry Res. 1989;28:193-213.
20. Ağargün MY, Kara H, Anlar Ö. Pittsburgh uyku kalitesi indeksi'nin geçerliliği ve güvenirliliği. Türk Psikivatri Dergisi.1996;7(2):107-15.

22. Cook J, Skikne B. Iron deficiency: definition and diagnosis. J Intern Med. 1989;226:349-55.

23. Beard JL. Iron deficiency and neural development: an update. Arch Latinoam Nutr. 1999;493:34-9.

24. Peirano PD, Algarín CR, Garrido MI, Lozoff B. Iron deficiency anemia in infancy is associated with altered temporal organization of sleep states in child hood. Pediatr Res. 2007;62:715-9.

25. Felt BT, Beard JL, Schallert T, Shao J, Aldridge JW, Connor JR, et al. Persistent neurochemical and behavioral abnormalities in adulthood despite early iron supplementation for perinatal iron deficiency anemia in rats. Behav Brain Res. 2006;171:261-70.

26. Lozoff B, Beard J, Connor J, Felt B, Georgieff M, Schallert T. Long-lasting neural and behavioral effects of iron deficiency in infancy. Nutr Rev. 2006;64:34-43. 27. Kim J, Wessling-Resnick M. Iron and mechanisms of emotional behavior. J Nutr Biochem. 2014;25:1101-7. 28. Dzirasa K, Ribeiro S, Costa S, Santos LM, Lin S-C, Grosmark A, et al. Dopaminergic control of sleepwake status. J Neurosci. 2006;26:10577-89.

29. Keating GL, Rye DB. Where you least expect it: dopamine in the pons and modulation of sleep and REMsleep. Sleep. 2003;26:788-89.

30. Holst SC, Bersagliere A, Bachmann V, Berger W, Achermann P, Landolt HP. Dopaminergic role in regulating neurophysiological markers of sleep homeostasis in humans. J Neurosci. 2014;34:566-73.

31. Fifel K, Vezoli J, Dzahini K, Claustrat B, Leviel

$\mathrm{V}$, Kennedy $\mathrm{H}$ et al. Alteration of daily and circadian
21. Beard J. Iron deficiency alters brain developmen and functioning. J Nutr. 2003;133:468-72.

hythms following dopamine depletion in MPTP treated non-human primates. PLoS One. 2014;23:9(1):e86240. 32. Pace-Schott EF, Hobson JA. The neurobiology of sleep: genetics, cellular physiology and subcortical networks. Nat Rev Neurosci. 2002;3:591-605.

33. Sadrzadeh SM, Saffari Y. Iron and brain disorders. Am I Clin Pathol. 2004;121:64-70.

34. Allen RP, Auerbach S, Bahrain H, Auerbach M, Earley CJ. The prevalence and impact of restless legs syndrome on patients with iron deficiency anemia. $A m \mathrm{~J}$ Hematol. 2013;88:261-4.

35. Akyol A, Kiylioglu N, Kadikoylu G, Bolaman AZ, Ozgel N. Iron deficiency anemia and restless legs syndrome: is there an electrophysiological abnormality? Clin Neurol Neurosurg. 2003;106:23-7.

36. Onder G, Penninx BW, Cesari M, Bandinelli S, Lauretani F, Bartali B, Gori AM, Pahor M, Ferrucci L. Anemia is associated with depression in older adults: results from the InCHIANTI study. I Gerontol A Biol Sci Med Sci. 2005;60:1168-72.

37. Son SJ, Lee KS, Na DL, Seo SW, Kim CH, Kim JH et al. Anemia associated with depressive symptoms in mild cognitive impairment with severe white matter hyperintensities. J Geriatr Psycbiatry Neurol. 2011;24:161-7. 38 Yehuda S, Rabinovitz-Shenkar S, Carasso RL. Effects of essential fatty acids in iron deficient and sleep-disturbed attention deficit hyperactivity disorder (ADHD) children. Eur J Clin Nutr. 2011;65:1167-9.

39. Yehuda S, Yehuda M. Long lasting effects of infancy iron deficiency--preliminary results. J Neural Transm Suppl. 2006;71:197-200.

40. Vahdat Shariatpanaahi M, Vahdat Shariatpanaahi Z, Moshtaaghi M, Shahbaazi SH, Abadi A. The relationanxiety in patients with nasal septal deviation. Sleep and 